\author{
VI International Forum on Teacher Education
}

\title{
Digital Electronic Space as the Foundation of Music Teacher Training
}

\author{
Margarita M. Zabbarova* (a), Irma R. Levina (b), Elena A. Moroz (c), Tatyana I. \\ Politaeva (d)
}

(a), (b), (c), (d) Bashkir State Pedagogical University n.a. M. Akmulla, 450000, Ufa, 3 a October

Revolution street, zabbarova74@mail.ru

\begin{abstract}
The massive interest and enthusiasm for musical art on a digital basis is high today. Electronic tools attract with their accessibility and multi-timbral colorfulness. The computerization of music education, modern educational standards in the new WorldSkills movement paradigm, the relevance of the development of media education and self-educational technologies to improve the professional self-development of a modern music teacher determine the problem of researching and substantiating modern forms of electronic-creative music making - arranging as a means of digital electronic space.

Available information on the problem requires a systematization of arrangement knowledge and skills based on digital electronic space. This determined the purpose of the study, which is to create working conditions for the arrangement and design supporting electronic content in the form of digital electronic space for the self-development of relevant skills by a music teacher.

An analysis of the concepts revealed the pedagogical tools for constructing the arranging process, determined the consideration of composition and electronic arranging skills as the main methods of sound intonation and re-intonation of the musical sense of music, and contributed to the presentation of the substantive side of the musician's universal competence. The computer-musical shell as a "digital electronic space" should possess all the features of a training system where books and articles on arrangement will be studied, individual practical implementation of musical tasks independently chosen by the user according to the level of complexity and time of execution, with the possibility of self-control (testing knowledge and skills). Only in this case a comfortable educational environment will arise when the student will be able to independently carry out macro navigation and form their own learning routes.
\end{abstract}

Keywords: digital electronic space, music teacher training, arrangement.

(C) 2020 Margarita M. Zabbarova, Irma R. Levina, Elena A. Moroz, Tatyana I. Politaeva

This is an open access article distributed under the terms of the Creative Commons Attribution License (CC BY 4.0), which permits unrestricted use, distribution, and reproduction in any medium, provided the original author and source are credited.

Published by Kazan federal university and peer-reviewed under responsibility of IFTE-2020 (VI International Forum on Teacher Education)

* Corresponding author. E-mail: zabbarova74@mail.ru 


\section{Introduction}

The study of the problem of teacher training is one of the leading tasks of top-level pedagogy, as well as the development of a socially active person, able to meet all the challenges of the modern educational situation, the ability to engage in self-education, develop one's creative abilities, and effectively use all the resources offered in the education system.

The professional training of a modern music teacher at university involves many areas, i.e. the training in innovative technologies in the field of pedagogy and psychology, the development of musical art samples, the formation of intellectual potential and creative abilities, as well as work in digital electronic space.

The relevance of the study is due to the growing interest of people and their enthusiasm for musical art on an information-computer basis. Music and computer technology attract with its accessibility and multitimbral colorfulness. It is important to note that future music teachers should be able to use the types, forms and means of digital electronic space - electronic arrangement products created on the basis of modern computer-music applications and electronic musical instruments (synthesizers and workstations), as these technologies motivate children and introduce them to the musical culture. In educational institutions of our time, a significant number of methods for obtaining education are organized. The impact of digital electronic space means an increase in the number of methods for obtaining music education and selfeducational activities.

Therefore, the problem of training a music teacher based on digital electronic space is of great importance.

\section{Purpose and objectives of the study}

The aim of the article was an empirical test of the use of digital electronic space in the training of a music teacher.

\section{Literature review}

In the theory and practice of musical and pedagogical education, a certain vision of the professional training of a music teacher has developed. Research in the field of computer technologies reflecting the modern vision of scientists on the use of digital electronic means in the educational space of the university is presented.

The theory and practice of preparing a future music teacher is revealed in the works of Abdullin (2012), Aliyev (2000), Levina (2019), Toropova (2017). In particular, Abdullin (2012) lays the foundations for the 
professional training of a teacher using modern educational technologies. Toropova (2017) points to the psychological component of education at university and highlights the features of the reaction of a person's consciousness to innovations taking place in society, including education. Levina (2019) writes about the social significance of the musical and creative development of the personality of the future teacher.

A well-known researcher of music and computer technologies and their use in the education system, Gorbunova (2004) defines the main areas of using digital electronic space: in specialized education as a way of developing the creative potential of an individual; in educational institutions as a tool for educational activities; as a method and tool for self-education of children and adults; as a tool to restore the abilities of people with disabilities; in the process of learning in subjects related to digital resources and the study of multimedia ways of presenting information; as a process of an educational path for educating experts in the field of digital electronic space, as well as in the formation of new directions in educational institutions of general, secondary specialized and higher education.

The topic of introducing music and computer technologies is studied in the works of Krasilnikov (2007) and Zabbarova (2018), which reveal the essence, educational and developing potential of digital electronic space as a new type of educational and artistic activity. In particular, Krasilnikov (2007) offers a number of teaching aids on organizing music education using digital resources of schoolchildren based on children's music schools.

Education of students - future music teachers on the basis of digital electronic space in higher education is substantiated by Zabolotskaya (2000), Priselkov (2003), Polozov (2002), Taraeva (2007). For example, Polozov (2002) suggests using educational computer programs for the development of the personality and creative abilities of the teacher. For our study, the ideas of Gorbunova (2004) and Krasilnikov (2007) become important, which reveal the enormous role of the computer in the creative development of a person's personality and offer psychological and pedagogical conditions for using them in the training of a future music teacher.

Peshnyak (2002) and Zhivaykin (2004) reveal the capabilities of the synthesizer as one of the tools of the digital electronic space in learning, influencing the creative development of the future teacher, which must be studied at the stage of university education, since this instrument is popular among children.

\section{Methodology}

Digital electronic space is a system of musical and computer tools for use in the system of educational practice at any level. In our field of vision is the preparation of a future music teacher based on digital electronic means. The 
space is created by the presence of musical and electronic instruments, musical and computer programs and forms of working with them, using technologies and techniques for working with digital resources when teaching a future musician teacher.

Today, there are a large number of electronic platforms - sites of universities, educational portals, virtual universities, covering the use of digital electronic space in the system of higher music education. Music teachers can learn this type of musical activity through short-term electronic refresher courses, visiting private organizations in the form of virtual music schools with tutors, or getting to know individual distance learning demos. A lot of useful information can be found on the Internet networks on arranging issues (in electronic magazines, articles, forums, chats). However, we note that all the available information does not have a certain systematic nature, which complicates its search, processing, perception and practice of mastering the skills of composition and arrangement. Hence, we believe that in modern conditions of informatization of music education, in addition to curricula and plans for training musicians, a virtual music-computer training system "Tutor - arranger agent" will be useful as an assistant-tutor, a specialized electronic self-educational environment that will expand a teachers' musical creative library and allow them to easily prepare for the educational process.

Let us describe the content of the digital electronic space we model for a modern musician. It is based on one of the creative forms of playing music - an arrangement that uses the most universal means and methods of digital electronic space.

Arrangement is a type of musical and creative activity in which the original music is modified (transcription, processing), up to its global transformations, the degree of which depends on the artistic and performing tasks set by the arranger. At the same time, both the whole work and the musical motive can serve as the original for the arrangement, and the artistic result is a change in the sound quality of the work due to the renewal of its instrumental composition, and hence the style of performance. This means that the process of arrangement is mainly aimed at the processes of "stylization" and renewal (modernization) of musical material. It directly depends on musical knowledge, creative skills of intoning musical material and its reintonation - interpretation, in other words - on the skills of composition as one of the primary constituent elements of electronic music creativity, as asserted by Krasilnikov (2007). This determines the importance of this type of art as a universal way of developing the musical culture of society. In addition, according to Zabbarova (2018), reliance on different-level functions of arrangement, the main of which are social and personal transforming, should be used in professional music education in terms of their educational potential.

It should be remembered that music is always a part of the general culture. In the modern world, where music is often the context of socio-cultural events and has an applied meaning, mastering the art of "arranging for the 
occasion" for a modern creative person (especially a musician) is necessary, and it should start with solving the problems of competent interpretation of contexts, and then move on to the independent creation of contextual music (to stage events, plots). Deciphering media texts and interpreting various musical interpretations develops media literacy, requires knowledge of the laws of hermeneutics and the apparatus of semantics, the theory of musical content. In music education, as Shaimukhametova (2015) notes, the analysis of the actual content, semantic components, as a rule, is replaced by verbal-associative, sensory-intuitive characteristics, that are not always adequate to the author's intention. In this regard, it is necessary to learn how to use universally significant intonations and to include them in free music making and improvisation. This is one of the main tasks of teaching future music teachers. Cognition of the essence of musical content is impossible without studying the history of the creation of the work, biographical information about the composer, as well as studying semantic figures, the expressiveness of melodic figures, and the quality of the metro rhythm.

Perceiving the essence of musical content is impossible without studying the history of the creation of the work, biographical information about the composer, as well as studying semantic figures, the expressiveness of melodic figures, the quality of the metro rhythm. Shaimukhametova (2015) believes that the dignity of musical hermeneutics lies in the development of artistic imagination in people who deal with art. But it deals only with the figurative side of music and does not cover compositional elements as the semantics needed by an arranger.

The versatility of arranging skills is also due to the emergence of modern musical and computer technologies, which create the basis for the digital electronic space and open up wide creative possibilities for choosing musical and artistic means of sound embodiment of an artistic intention in a work, for increasing musical skill and creative self-realization. In addition, according to the conceptual theory of electronic musical creativity by Krasilnikov (2007), a new type of work and product of musical creativity - electronic arrangement - includes and uses all the main links of the communicative chain of playing music in ontogeny and phylogeny. These are the autocommunications of the improviser, the communication of the performer, composer and sound engineer, the programmer-creator of electronic sounds and the user with modern electronic musical instruments, activating the musician's skills in instrumental playing, composing, and experimenting with sound, and analytical listening.

In this regard, the training and arrangement process is a complex structural and educational system that, from a professional point of view, requires a great deal of time, intellectual and energy efforts to master the relevant skills, including independent work skills in musical self-development and self-education.

Adhering to the point of view of art scholars, Ryabchevskaya (2006) writes that any artistic masterpiece is a value. And value in the limit is an "eternal" value, that is, one that is "not subject" to historical vicissitudes and changes. In this regard, the goal of training a musician should be to master the arrangement as a way to create 
highly artistic expressive and memorable musical material using musical intonation of artistic meaning, as well as processing popular melodies.

The next point is to determine the range of creative tasks for the development of the musical culture of the musician-arranger, namely the demanded genre forms of creative music-making. Here one should rely on the analysis of the concepts of cultural development. Today in the scientific world there are many of them, but at the center of any of them is a person - a subject, a bearer of a certain culture and social relations. In this case, the universal formula of cultural development revealed in the science of cultural studies becomes relevant, through the prism of which it is possible to trace the development of any aspect of social consciousness, including musical art (Ryabchevskaya, 2006).

The first is an inversion type of domestic cultural dynamics with a characteristic dependence on the prevailing social idea, when at each stage of the development of music, dual oppositions are identified that are necessary for studying, for example, the spiritual and secular direction, the St. Petersburg school and the Moscow school, Taneyev and Scriabin; Scriabinists and Prokofiev, elite and mass genres (Ryabchevskaya, 2006).

The second type is ternary, characteristic of Western culture, "in which binarity (duality, polarity) is complemented by a third middle element, which ensures gradualness, an evolutionary type of development. It is "middle", where there are no extremes. The "middle" as a cultural innovation arose as a result of overcoming duality in culture through the search for a new measure of resolving polar points of view on a cognizable object through the creative build-up of a new cultural content. The mediation logic prevailing in the West "defined the ability of a Western person to know him/herself as an autonomous and self-realized person, forming a middle “culture" (Davidov, 2001, p. 68).

According to the existing two types of cultural development, the set musical and stylistic tasks of arrangement must correspond.

Since, according to scientists, "mediation is the process of forming previously unknown alternatives that did not exist in a given culture, and the inversion logic is an extreme case of mediation" (Ryabchevskaya, 2006, p. 140), it is advisable to start studying the musical language with polar musical styles in an arrangement, then based on the various classical domestic and foreign traditions to study more modern musical directions, and then search for their own alternatives.

The methods and principles of ordering the arrangement process should be determined by another equally important scientific position. According to the aesthetics of autonomy in the 19th century and the aesthetics of the context, the musical meaning is the result of the work of the listener's consciousness. Therefore, the 
educational process should be based on "comparative listening to music" (Politaeva, 2019), as a means of enriching personal intonation experience, a support base from musical performances and impressions that affect the depth and richness of the individual style of the author-arranger.

At the same time, according to the aesthetics of autonomy, in music the attention of the arranger should be focused on the logical aspect of the musical fabric, and according to the aesthetics of the context, on the emotional and associative aspect. Also, one should take into account other scientific studies of the supporters of the aesthetics of autonomy, who substantiated the change in musical eras and styles. For example, Ryabchevskaya (2006, p. 141) substantiated that "the a priori reason in the field of natural qualities of instrumentation, sound, and timbre and line are identified as opposites of vertical and horizontal, the constant balancing of which is the search for that very "middle path" in the logic of the development of musical history", which should lead to the study of both homophonic-harmonic and various polyphonic linear styles, including the style of avant-garde trends in music.

In this regard, in order to improve the technique of musical texture writing, it is necessary to begin by imitating the stylistics of the most prominent composers - icons of the classical style, to study their scores, works on instrumentation.

To implement the development of a student's preparedness for work in digital electronic space for future work at school in the form of class and extracurricular work at the stage of university education, certain materials must be used: video tutorials on certain topics, music-oriented audio files, educational music programs, interactive technology of interaction with the learner. These types of material are transferred by the teacher to digital storage media. Depending on the type of material, the teacher has the opportunity to direct the student to independently search for such material in the media.

In the course of work on the formation of certain skills of using digital electronic space as a future music teacher, it is necessary to highlight these types and methods of educational activity in the learning process at university:

1. Formation of a personal collection of educational multimedia material for each student, and a collection of materials for working in music lessons at school;

2. Selection and classification of educational multimedia material necessary for independent arrangement activities, the results of which can be applied during the educational process;

3. Building a subject line at the university, taking into account further work at school and solving common problems in the development and use of means and resources of digital electronic space. 
The main incentive for a student to be able to independently advance in the musical art and use the resources of digital electronic space is an individual focus on musical and educational work. With the effective use of skills and abilities in the student's personal musical aspirations, the personality develops harmoniously.

During the pilot study, we identified three main criteria, which, in our opinion, can provide the desire of future music teachers to master the means of digital electronic space on the basis of self-education and self-study of musical disciplines at the university related to the specifics of the profile.

An important point is the manifestation of the interest of future music teachers in the development of musical and theoretical skills and performing abilities in the process of self-learning. The development of interest using multimedia musical and computer technologies in the process of self-educational activity will become a factor in stimulating cognitive, productive and creative musical activity, which is the basis for the dynamic development of musical and creative abilities and personal qualities, and leads to the cultural enrichment of an adult's personality.

Therefore, the first criterion was the formation of motivation for the development of musical and performing disciplines in the process of self-educational activity. Motivation acts as a driving mechanism in the development of musical disciplines according to personal educational needs. The problem of the student's lack of motivation to study various sciences is caused by the lack of free time for education, the complexity of the disciplines or the supply of information for mastering, the manifestation of unwillingness to study activity due to a lack of understanding of the subject. To solve this series of problems, it is necessary to provide the future teacher with a tool for simple but effective training and development with the availability of the information and material provided in the process of self-education.

The second criterion is a set of skills for carrying out actions and operations in musical and computer activities all kinds of ways to generate, edit and exchange information, which include basic, key universal and special musical and computer competencies, abilities and skills.

The third criterion we determined the readiness for self-control in the process of self-educational activity. This criterion is carried out by the ability of future music teachers to analyze their own actions and evaluate their work, while taking into account the mistakes made in the process of self-education and finding rational ways to eliminate them.

The above criteria are important not only in the process of self-educational work, but also are important in vocational training in the system of higher musical and pedagogical education. Without the formation of interest in musical disciplines, in the absence of motivation to study them, all learning activities will be 
ineffective both within the educational process and in self-educational work. The lack of self-control ability will lead to the fact that the student will not be able to productively and correctly obtain knowledge and skills in the process of self-education.

The research sample included two groups of students studying at the M. Akmulla Bashkir State Pedagogical University with a major in "Musical Education" in the first, second and third courses. The age of students in this group ranged from 18 to 20 years.

A preliminary interview showed that students have a cognitive interest in keyboard digital musical instruments, which has not yet been realized for one reason or another. An exception was a few participants who reported a lack of interest in digital media, making it difficult to work with them. It should be noted that all students had good knowledge and abilities associated with the use of information and computer technologies.

The main research method that was used in the experiment was the questionnaire of students. The questionnaire in our study is considered as a way of collecting data about the objects of research during the work of teachers and the students by taking into account their answers to questions formulated by the teacher, revealing their educational results in accordance with the purpose and objectives of the study. The questionnaire was conducted in anonymous form. This form of work allowed the research subjects to provide direct answers to the questions posed by the teacher, as well as to build students' confidence that their opinion is of particular importance for the results of the pedagogical experiment. The questionnaire consists of three groups of questions with four possible answers. The first group consists of three questions revealing information on the formation of the first criterion for the student to be interested in developing musical and theoretical skills and performing abilities in the process of self-learning using digital resources. The second group of questions, similarly to the first, consists of three questions revealing information on the formation of musical and computer skills for the development of musical and performing skills of arranging activities. The third group of questions reveals information about the formation of readiness for future self-control of a music teacher in the process of professional activity.

The answers to these questions contain a scoring system that reveals the essence of the formation of the criterion. The maximum possible number of points within one group of questions is twelve points, while the minimum value reaches three points. After calculating the total number of points for all three groups of questions, the maximum and minimum values of which can reach thirty-six and nine points, respectively, a final percentage ratio is formed that displays the student's readiness for self-education.

The pedagogical experiment consisted of three stages: ascertaining, formative and control.

At the first stage, we selected the compositions of the experimental and control groups. The composition of the experimental and control groups was identical, due to the fact that the pedagogical experiment concerned each 
subject and was carried out in a comparative analysis of different types of classes, rather than individual students. At this stage, both groups worked according to their schedule, which corresponds to the curriculum. At the same time, specially digital electronic means were not involved in learning. The training was conducted according to standard methods of presenting information using a theoretical explanation and its implementation in practice.

From the first lessons, there was a lack of active interest in musical disciplines on the part of subjects, a lowinitiative mood. In the process of an independent form of training implemented in the form of homework, students experienced difficulties in developing arrangement skills in practical actions.

Following the lessons, students of both groups were asked to undergo an anonymous survey, implemented in the form of questionnaires.

Table 1. Results of the survey at the ascertaining stage

\begin{tabular}{|l|l|l|l|l|}
\hline \multirow{2}{*}{ groups } & \multicolumn{2}{|l|}{ Readiness criteria student self-education } & \\
\cline { 2 - 4 } & motivation & operating & self control & \\
& & & & Total \\
& & & & (points / percent) \\
\hline $1(\mathrm{EG})$ & 5 & 6 & 5 & $16 / 44.4 \%$ \\
\hline $2(\mathrm{CG})$ & 4 & 4 & 3 & $11 / 30.5 \%$ \\
\hline
\end{tabular}

Based on the results of the first questionnaire, it should be noted that the formation of criteria for the readiness of students to conduct self-educational activities in the digital electronic environment in the framework of standard teaching methods is not enough and a total of $44.4 \%$. In the framework of this questionnaire, the criterion for motivation for musical self-educational activity reaches average values, in contrast to other criteria. This value indicates the need for the development of an operational criterion and readiness for self-control in conjunction with the motivational aspect.

At the formative stage of the experimental work with the experimental group of students, a cycle of four lessons was organized using digital electronic space. In the classes on arranging, playing the keyboard instrument, as 
well as in the rest of the classes, the introduction of music and computer technologies into the educational process and the self-education of the students of the experimental group were carried out using verbal, practical, as well as visual teaching methods.

In the educational process, electronic-keyboard instruments were used, as well as programs for arranging activities. The first lesson is devoted to the device and connecting a MIDI keyboard to a personal computer and the Steinberg Cubase software sequencer, which provide access to multimedia opportunities in the learning process, open up broad prospects for creativity. The students showed interest in the technical device and the functional purpose of the electronic keyboard instrument, asked questions about the use of this instrument in musical art. The participants learned how to rely on the algorithms of action given by the teacher to independently use the tool in creative forms of work on a personal computer, which contributed to the formation of interest in the further study of the arranging process. The second lesson revealed the purpose of keyboard synthesizers-workstations CASIO WK 6600, YAMAHA PSR S-670, as well as Synthesia software visualizer, their interface and functional training capabilities, through which the process of developing musical performing and arranging skills is carried out. The lesson revealed the process of studying musical works using computer technologies, the visibility and visual component of which increased the students' interest in the development of arranging activities. In this case, the teacher's task was to monitor interest, develop motivation and support students in mastering arranging skills - auxiliary displays of computer operations and answers to questions that arise during the work. The third lesson was the most basic in the whole cycle, and revealed the process of studying a musical work using the functionality of hardware and software sequencers, the Synthesia keyboard visualizer, discussed in the previous lesson. The main task of the experimental group was the possibility of independent selection of musical compositions for analysis and arrangement, including the study of the selected work from the built-in list of Synthesia keyboard visualizer.

The students independently completed the exercise using the visual means of presenting musical information in the form of drop-down keys in the keyboard visualizer interface, which positively affected the motivation for the further use of this software product for the development of musical and performing skills in playing keyboard instruments. The final fourth experimental lesson revealed the possibility of loading third-party musical works and arrangements into the aforementioned instrumentation. In this lesson, the student's interest in certain musical compositions and individual opportunities to study and arrange the selected work were taken into account. This lesson was used to consolidate the learner's interest in using digital electronic tools in the process of self-education. 


\section{Results}

After conducting a series of experimental studies with the students of the experimental group, discussions were held on the results of studying the Electronic Tour of Arrangement. This determined that the use of music and computer technologies in the process of studying electronic arrangement led to an increase in the criteria for self-education of students. The use of visual materials, providing simple, at the same time accessible information on musical disciplines, made the students orient on the path to self-improvement of musical skill and independent acquisition of skills and abilities.

Following a discussion with the participants of both groups, it was proposed to go through questionnaires.

Table 2. The results of the survey at the control stage

\begin{tabular}{|l|l|l|l|l|}
\hline \multirow{2}{*}{ groups } & \multicolumn{2}{|l|}{ Readiness criteria student self-education } & \\
\cline { 2 - 4 } & motivation & operating & self control & \multirow{2}{*}{ Total } \\
& & & & (points / percent) \\
\hline $1($ EG) & 10 & 11 & 10 & $31 / 86.1 \%$ \\
\hline $2(\mathrm{CG})$ & 4 & 4 & 3 & $11 / 30.5 \%$ \\
\hline
\end{tabular}

Based on the results of the second questionnaire, it should be noted that the formation of the criteria for the readiness of students to conduct self-educational activities based on the use of digital electronic space in the experimental group has grown significantly.

\section{Discussions}

Comparison of the overall final result showed that the readiness indicator of future music teachers for selfeducation through the use of digital electronic space is significantly higher than that of students in the control group who conducted classes according to the standard academic plan.

As a result of the lessons developed, as well as active and visual methods of working in the educational process of preparing future music teachers, significant changes were identified for each selected criterion. 
The results of the pedagogical experiment confirm the substantiated hypothesis of the study that the use of digital electronic space in the process of training future music teachers will contribute to the development of musical and creative abilities, provided that the student develops motivation, operational and computer skills in mastering arrangement activities and self-control abilities.

\section{Conclusion}

In the course of the pedagogical experiment, we came to the following conclusions.

Criteria of students' willingness to work with digital electronic resources in the process of training directly depend on the method of teaching material. Presentation of information in a standard form does not contribute to the formation of these criteria for a future music teacher, but, on the contrary, produces a demotivating effect.

Students' interest and motivation must be formed using digital electronic space, which should be introduced into the process of university education. For the effective presentation of the material, it is necessary to consider the use of all teaching methods. The use of verbal methods paired with visual demonstration teaching methods contribute to the correct provision and assimilation of information, and the practical method forms a competent consolidation of the material in practice. If the formation of certain musical and computer operations depends on the availability of supporting materials and auxiliary training functions and demonstrated operations on digital instruments, then the formation of the ability of selfcontrol, as the final component of readiness, depends on certain forms and electronic means of verification in achieving creative results, and on personal motivated activities of the student.

It should be noted that, having built the educational process on an outstanding repertoire, it is possible to stimulate the success and achievements in this field among future music teachers, since arrangement as a valuable work of art becomes part of the development of musical culture. Thus, the use of digital electronic space in preparing the future music teacher for arranging activities opens up prospects for creative selfexpression of the individual.

\section{References}

Abdullin, E. B. (2012). On the problems of modern music and pedagogical education. In Actual Problems of Music and Pedagogical Education: Proceedings of X International Scientific and Practical Conference (pp. 7-14). Moscow: Ritm.

Aliyev, Yu. B. (2000). Handbook of a school music teacher. Moscow: Vlados. 
Gorbunova, I. B. (2004). The phenomenon of music and computer technologies as a new educational creative environment. Izvestia: Herzen University Journal of Humanities \& Sciences, 4(9), 123-138.

Davidov, A. A. (2001). "We languish with spiritual thirst": A.S. Pushkin and the formation of a "middle" culture in Russia. Novosibirsk: Sibirskiy khronograf.

Kholopova, V. N. (2015). Musical hermeneutics, musical semantics, musical content: A comparison of possibilities. Scholarly papers of Russian Gnesins Academy of Music, 1, 20-28.

Krasilnikov, I. M. (2007). Electronic musical creativity in the system of art education. [Doctoral Thesis, Moscow].

Levina, I. R. (2019). Social intelligence of a music teacher. Ufa: BSPU named after M. Akmulla.

Politaeva, T. I. (2019). Musical arrangement is an important component of a modern music lesson. Pedagogical Journal of Bashkortostan, 5(84), 51-61.

Peshnyak, V. G. (2002). Tutorial for playing the synthesizer CASIO STK-731 (I. Glushchenko, Ed.). Moscow.

Priselkov, A. S. (2003). Computer technologies in the formation of professional creative activity of musicians. [PhD Thesis, Krasnodar].

Polozov, S. P. (2002). Teaching computer technologies and music education. Saratov: Saratov University Publ. House.

Ryabchevskaya, Zh. A. (2006). Musical culture in a binary and ternary type of sociocultural dynamics. Kemerovo State University of Culture and Arts, 1(1), 139-145.

Taraeva, G. R. (2007). Computer and innovation in music pedagogy. Book 1: Strategies and Techniques. Moscow: Klassika-XXI.

Toropova, A. V. (2017). Phenomenology of the intoning function of musical-linguistic consciousness. [Doctoral Thesis, Moscow].

Shaimukhametova, L. N. (2015). On the concept of scientific development of the laboratory of musical semantics of UGAI named after Zagira Ismagilova. Problems of Oriental Studies, 3(69), 61-67. 
Zabbarova, M. M. (2018). Information technology as a factor of self-education of a future music teacher. Ufa: BSPU named after M. Akmulla.

Zabolotskaya, I. V. (2000). New information technologies in music education. [PhD Thesis, Saint Petersburg].

Zhivaykin, P. V. (2004). Virtual synthesizers. Music and Electronics: "Musical software”, 3, 14-15. 